\title{
Market Power and Asset Contractibility in Dynamic Insurance Contracts
}

\author{
Alexander K. Karaivanov and Fernando M. Martin
}

\begin{abstract}
The authors study the roles of asset contractibility, market power, and rate of return differentials in dynamic insurance when the contracting parties have limited commitment. They define, characterize, and compute Markov-perfect risk-sharing contracts with bargaining. These contracts significantly improve consumption smoothing and welfare relative to self-insurance through savings. Incorporating savings decisions into the contract (asset contractibility) implies sizable gains for both the insurers and the insured. The size and distribution of these gains depend critically on the insurers' market power. Finally, a rate of return advantage for insurers destroys surplus and is thus harmful to both contracting parties. (JEL D11, E21)
\end{abstract}

Federal Reserve Bank of St. Louis Review, Second Quarter 2016, 98(2), pp. 111-27. http://dx.doi.org/10.20955/r.2016.111-127

\section{INTRODUCTION}

Households face fluctuations in their incomes but desire stable consumption. Prime examples of shocks to income are variations in labor status and changes in health. Maintaining savings in liquid and low-risk assets-for instance, in the form of government bonds or savings accounts-allows households to mitigate the impact of negative income shocks on their standard of living. Similarly, positive income shocks provide the opportunity to accumulate savings to use in bad times. However, savings are an imperfect way to insure against idiosyncratic shocks: For instance, the return on a deposit does not increase because the depositor is laid off or sick. Hence, a natural way to complement self-insurance through savings is to contract with an insurer (private or government-run) willing to absorb an agent's individual risk. In a perfect world, the parties would sign a long-term contract that maximizes the surplus generated by the relationship and fully specifies the time paths of consumption and savings of the insured for all possible combinations of future income states.

In practice, however, economic actors often cannot commit or are legally barred from committing to a long-term contract. For example, consider typical labor, housing, and personal or property insurance contracts: Costless renegotiation or switching providers is always

\footnotetext{
Alexander K. Karaivanov is a professor of economics at Simon Fraser University. Fernando M. Martin is a senior economist at the Federal Reserve Bank of St. Louis. Alexander Karaivanov acknowledges the financial support of the Social Sciences and Humanities Research Council of Canada (grant No. 435-2013-0698).

○ 2016, Federal Reserve Bank of St. Louis. The views expressed in this article are those of the author(s) and do not necessarily reflect the views of the Federal Reserve System, the Board of Governors, or the regional Federal Reserve Banks. Articles may be reprinted, reproduced, published, distributed, displayed, and transmitted in their entirety if copyright notice, author name(s), and full citation are included. Abstracts, synopses, and other derivative works may be made only with prior written permission of the Federal Reserve Bank of St. Louis.
} 


\section{Karaivanov and Martin}

possible, although sometimes only at fixed time intervals. In addition, while insurers are frequently aware of an agent's net worth or assets, they may or may not have the ability to control private asset accumulation. The latter ability, however, can be key to the interplay between self-insurance and market- or government-provided third-party insurance (e.g., Arnott and Stiglitz, 1991). As an example, government social security schemes (old-age insurance) usually have both voluntary and controlled/forced savings components. Various mixtures of components exist around the world.

We study the above issues and trade-offs in a multiperiod risk-sharing setting that features a risk-neutral insurer and a risk-averse agent endowed with a stochastic income technology and the ability to save at a fixed rate of return. We assume that the parties cannot commit to a long-term contract: Both the agent and the insurer can commit only to one-period risksharing contracts. In this setting, we show that there are still large gains from third-party insurance and the ability to incorporate the agent's savings decisions into the insurance contract.

Specifically, we model the interaction between the agent and insurer by assuming that they periodically bargain over the terms of the contract. Formally, we do so by adopting the solution concept of a Markov-perfect equilibrium (MPE), as in Maskin and Tirole (2001). This solution captures our notion of limited commitment, since contract terms are a function of only payoff-relevant variables (in our setting, the agent's assets and the income realization) and the idea that bygones are bygones. That is, the past does not matter beyond its effect on the current state.

We find that the agent's asset holdings are a key feature of Markov-perfect insurance contracts, as the assets determine the agent's endogenous outside option. Given that feature, we analyze the role of asset/savings contractibility by comparing the case of "contractible assets" (when the insurer can fully control the agent's savings decisions) with the case of "noncontractible assets" (when the agent can privately decide on the amount of his savings, even though the asset holdings are observed by the insurer). In many situations, governments, insurance companies, banks, and so on may have information about agents' assets but, for legal or other reasons, are unable to directly control agents' savings choices. In other situations-for example, social security - the opposite is true.

We show that asset contractibility affects the insurance contract terms and the degree of achievable risk-sharing compared with self-insurance, except in the limit when insurance markets are perfectly competitive (free entry). Intuitively, whenever the insurer has market power (not necessarily monopoly power) and thus can generate positive profits from insuring the agent, private asset accumulation provides the agent with an instrument to "counter" the insurer by controlling his future outside option. Essentially, larger savings by the agent today imply a larger outside option tomorrow since the agent would be better able to selfinsure. On the insurer's side, however, a larger outside option for the insured implies lower profits. We show that this misalignment of incentives between the contracting parties, which originates in the commitment problem, causes a welfare loss to both sides when the agent's assets are non-contractible.

Numerically, we assess the degree to which the presence of third-party insurance improves agents' welfare beyond that achievable on their own through savings. We show that the wel- 
fare gains for the poorest agents (zero assets) can be as high as 4.5 percent of their autarky consumption per period. This number is significantly larger than the cost of business cycle fluctuations (about 0.1 percent), a common benchmark for welfare calculations in macroeconomic applications. In terms of the role of asset contractibility, the largest welfare loss if agents' savings are non-contractible is about 0.4 percent of autarky consumption per period.

We also find that the market power of insurance providers significantly affects the welfare gains that agents derive in Markov-perfect insurance contracts and, to a lesser extent, the welfare losses when agents' assets are non-contractible. The welfare gains from third-party insurance are strictly decreasing in the insurers' market power, whereas the welfare costs of asset non-contractibility peak at an intermediate value of market power, somewhere between the monopolistic insurer case and perfectly competitive insurance markets.

Finally, our numerical results suggest that both the insured and the insurer are better off if there is no return on assets differential between them. A higher intertemporal return-or, equivalently, discount rate-for the insurer relative to the insured reduces the total surplus that can be generated in the risk-sharing relation. Furthermore, differences in the parties' rates of return on assets amplify the distortions in the time profiles of consumption and savings (relative to the equal return benchmark) that arise from the limited commitment friction.

Our article builds on and extends in several dimensions our previous analysis (Karaivanov and Martin, 2015). In that article, we introduced the idea of Markov-perfect insurance contracts and showed that limited commitment on the insurer's side is restrictive only when he has a rate of return advantage over agents with sufficiently large asset holdings. The limited commitment friction makes assets carried by agents essential in an MPE, as they cannot be replaced with promises of future transfers. In contrast, if the insurer and the insured have equal rates of return on carrying assets over time, we showed that Markov-perfect insurance contracts result in an equivalent consumption time path as a long-term contract to which only the insurer can commit because assets and promised utility are then interchangeable. While we retain the basic idea of Markov-perfect insurance, our analysis here differs in two important aspects. First, unlike in Karaivanov and Martin (2015), we allow agents' assets to be non-contractible. Second, instead of assuming an arbitrary asset-dependent but otherwise exogenous outside option for the agent, we endogenize the division of the gains from risksharing by defining and analyzing a bargaining problem between the parties.

This article also differs from the literature on optimal contracts with hidden savings (see Allen, 1985, and Cole and Kocherlakota, 2001, among others) that assumes that the principal has no ability to monitor the agent's assets. The main result in these articles is that no additional insurance over self-insurance may be possible, unlike in this article. On the technical side, our assumption of observable assets (even if non-contractible) helps us avoid dynamic adverse selection and the possible failure of the revelation principle with lack of commitment (Bester and Strausz, 2001), while still preserving the empirically relevant intertemporal implications of savings non-contractibility.

More generally, in the dynamic mechanism design literature, allowing agents to accumulate assets in a principal agent relationship typically yields one of the following three results, depending on the specific assumptions about the information or commitment structure: 


\section{Karaivanov and Martin}

(i) An agent's assets play no role (when the insurer can control the agent's consumption). (ii) Assets eliminate the insurer's ability to smooth the agent's consumption beyond self-insurance (Allen, 1985, and Cole and Kocherlakota, 2001). Or (iii) the environment becomes highly intractable (Fernandes and Phelan, 2000, and Doepke and Townsend, 2006). In contrast, we show that Markov-perfect insurance contracts result in simple dynamic programs with a single scalar state variable and avoid the curse of dimensionality, including the case with noncontractible savings.

\section{THE ENVIRONMENT}

Consider an infinitely lived, risk-averse agent who maximizes discounted expected utility from consumption $c$. The agent's flow utility is $u(c)$, with $u_{c c}<0<u_{c}(c)$ and $u$ satisfying Inada conditions. ${ }^{1}$ The agent discounts the future by factor $\beta \in(0,1)$. Each period the agent receives an output/income endowment, which he can consume or save. Output is stochastic and takes the values $y^{i}>0$ with probabilities $\pi^{i} \in(0,1)$ for all $i=1, \ldots, n$, with $n \geq 2$ and where $\sum_{i=1}^{n} \pi^{i}=1$. Without loss of generality, let $y^{1}<\ldots<y^{n}$.

The risk-averse agent would like to smooth consumption over output states and over time. We assume that the agent can carry assets $a$ over time by means of a savings (storage) technology with fixed gross return $r \in\left(0, \beta^{-1}\right)$. Let $\mathbb{A}=[0, \bar{a}]$ denote the set of feasible asset holdings, where $\bar{a} \in(0, \infty)$ is chosen to be sufficiently large that it is not restrictive. In contrast, the lower bound on $\mathbb{A}$ is restrictive and represents a borrowing constraint. Assuming that assets cannot be negative means that the agent cannot borrow-that is, he can only save.

Suppose that the agent has no access to insurance markets and therefore can rely only on self-insurance through savings-running up and down a buffer stock of assets as in Bewley (1977). In this situation, which we label "autarky," the agent's optimal consumption and savings decisions depend on his accumulated assets and are contingent on the output realization. That is, given realized output $y^{i}$, the agent carries into the next period assets $a^{i} \geq 0$ and consumes $c^{i} \equiv r a+y^{i}-a^{i}$.

Formally, the agent's problem in autarky can be written recursively as

$$
\Omega(a)=\max _{\left\{a^{i} \geq 0\right\}_{i=1}^{n}} \sum_{i=1}^{n} \pi^{i}\left[u\left(r a+y^{i}-a^{i}\right)+\beta \Omega\left(a^{i}\right)\right]
$$

By standard arguments (e.g., Stokey, Lucas, and Prescott, 1989), our assumptions on $u$ ensure that the autarky value function $\Omega(a)$ is continuously differentiable, strictly increasing, and strictly concave for all $\mathrm{a} \in \mathbb{A}$. The autarky (self-insurance) problem is a standard "income fluctuation" problem, versions of which have been studied, for instance, by Schechtman and Escudero (1977) and Aiyagari (1994), among many others. The properties of the solution are well known: imperfect consumption smoothing ( $c^{i}$ differs across states with different $\left.y^{i}\right)$; consumption $c^{i}$ and next-period assets $a^{i}$ in each income state increasing in current assets $a$; asset contraction (negative savings) in the lowest income state(s); and asset accumulation (positive savings) for some range of asset holdings in the highest income state(s). 
Since the rate of return on assets is assumed to be smaller than the agent's discount rate, $r<\beta^{-1}$, the agent saves only to insure against consumption volatility. ${ }^{2}$ In particular, there is a precautionary motive for saving because the agent wants to mitigate the chance of ending up with zero assets, a situation in which he would be unable to self-insure against negative income shocks. Note that since assets provide the same return in all output states, the agent is unable to insure perfectly against income fluctuations. Thus, there is a demand for additional insurance as addressed in the next section.

\section{INSURANCE}

Suppose there exists a risk-neutral, profit-maximizing insurer. Throughout the article, we assume that the insurer can costlessly observe output realizations $y^{i}$ and the agent's assets $a$. The insurer can borrow and lend, without restrictions, at gross rate $R>1$. The insurer's future profits are also discounted at the rate $R$. The parameter $R$ can have either a technological or preference interpretation. The special case $r=R$ can be thought of as the insurer having the ability to carry resources intertemporally using the same savings technology as the agent. If, instead, $R=\beta^{-1}$, we can think of the agent and insurer as having the same discount factora standard assumption in the literature. In general, we allow $R$ to take any value between these bounds, as stated in Assumption 1 below.

Assumption $10<r \leq R \leq \beta^{-1}$, with $\mathrm{r}<\beta^{-1}$, and $R>1$.

\subsection{The Agent's Savings Decision}

Suppose the insurer, while observing the agent's assets $a$, cannot directly control the agent's savings decision-namely, the choice of $a^{\prime}$. We can think of the insurance arrangement between agent and insurer in any time period as the exchange of output $y^{i}$ for gross transfer $\tau^{i}$ (this includes the insurance premium or payoff in the different states of the world). Transfers are allowed to depend on the agent's accumulated assets $a$, since assets affect how much insurance the agent demands.

Suppose the agent is offered insurance for the current period. What is his savings decision given transfers $\tau^{i}$ ? Call period consumption $c^{i} \equiv r a+\tau^{i}-a^{\prime i}$, as implied by the insurance transfer $\tau^{i}$, the gross return on the agent's current assets $r a$, and the agent's savings decision $a^{\prime i}$. Let $v\left(a^{\prime i}\right)$ denote the continuation value for the agent carrying assets $a^{\prime i}$ into the next period. The function $v$ is an equilibrium object that depends on all future agent-insurer interactions, which in turn depend on the level of assets carried into the future. The consumption/savings problem of the agent can then be written as follows:

$$
\max _{\left\{a^{i}\right\}} \sum_{i} \pi^{i}\left[u\left(r a+\tau^{i}-a^{\prime i}\right)+\beta v\left(a^{i}\right)\right] .
$$

With the Lagrange multiplier $\xi^{i} \pi^{i} \geq 0$ associated with the non-borrowing constraint $a^{\prime i} \geq 0$, the first-order conditions are 


$$
-u_{c}\left(r a+\tau^{i}-a^{\prime i}\right)+\beta v_{a}\left(a^{i}\right)+\xi^{i}=0
$$

for all $i=1, \ldots, n$. In other words, given an insurance contract for the current period and anticipating future interactions (contracts) between the agent and the insurer, which yield the continuation value $v$, the agent's savings decision is characterized by

$$
u_{c}\left(c^{i}\right)-\beta v_{a}\left(a^{\prime i}\right) \geq 0 \text {, with equality if } a^{\prime i}>0 .
$$

When the agent's savings are non-contractible, the insurer must take into account the agent's savings decision given by (2) when deciding on the insurance transfers $\tau^{i}$. We call this the agent's incentive-compatibility constraint, as any insurance contract that allows the agent to make his own savings decisions must respect condition (2).

Below we also consider the alternative case in which the agent's savings can be specified (enforced) as part of the insurance contract. In this case, inequality (2) does not restrict the design of the insurance contract offered to the agent.

\subsection{Markov-Perfect Insurance}

We assume that the agent and the insurer can bargain over the insurance terms each period. The insurance contract is negotiated every period since we assume a limited commitment friction-neither the agent nor the insurer can commit to honor any agreement beyond the current period. This limited commitment friction could be motivated by legal, regulatory, or market reasons. For example, in many real-life situations (labor contracts, housing rental, home and car insurance, and so on) the parties are allowed to (costlessly) modify or renegotiate the contract terms at fixed points of time (e.g., yearly).

If the parties do not reach an agreement, they revert to their respective outside option from then on. Of course, given the limited commitment friction, both parties know that any agreement spanning more than one period is subject to renegotiation and cannot be committed to. The outside option for the agent is autarky, with value $\Omega(a)$ as derived previously. The outside option for the insurer is zero profits.

To model the bargaining game between the agent and the insurer, we adopt the Kalai (1977) solution, which picks a point on the utility possibility frontier depending on a single parameter $\theta$. This parameter can be interpreted as the agent's "bargaining power." Specifically, in Kalai's bargaining solution, a larger value of $\theta$ implies that the agent obtains surplus closer to his maximum feasible surplus, while the insurer obtains surplus closer to his outside option. The converse is true for lower values of $\theta$. The limiting case $\theta \rightarrow 1$ corresponds to the agent receiving his maximum possible surplus and the insurer receiving his outside option of zero profits. This situation can be interpreted as a market setting with perfect competition and free entry by insurers. In contrast, in the opposite limiting case, $\theta \rightarrow 0$, the agent receives his outside option, while the insurer receives maximum (monopoly) profits. Formally, the Kalai bargaining solution postulates a proportional surplus-splitting rule, which takes the form $(1-\theta) S^{A}=\theta S^{I}$, where $S^{A}$ is the agent's surplus, defined as the difference between the agent's value in the contract and his outside option, and $S^{I}$ is the insurer's surplus, defined analogously. 
Let $\bar{y} \equiv \sum_{i=1}^{n} \pi^{i} y^{i}>0$ denote expected output. The insurer's expected period profit is therefore $\bar{y}-\sum_{i=1}^{n} \pi^{i} \tau^{i}$. Equivalently, using $c^{i}=r a+\tau^{i}-a^{\prime i}$, we can rewrite the insurer's profit in terms of the agent's consumption and next-period assets as $\bar{y}+r a-\sum_{i=1}^{n} \pi^{i}\left(c^{i}+a^{i}\right)$. The participation constraints of the contracting parties are therefore

$$
\begin{aligned}
& \sum_{i=1}^{n} \pi^{i}\left[u\left(c^{i}\right)+\beta v\left(a^{\prime i}\right)\right] \geq \Omega(a) \\
& \bar{y}+r a-\sum_{i=1}^{n} \pi^{i}\left[c^{i}+a^{\prime i}-R^{-1} \Pi\left(a^{\prime i}\right)\right] \geq 0,
\end{aligned}
$$

where $v$ and $\Pi$ denote the (endogenous) agent and insurer continuation payoffs, respectively, both as functions of the agent's asset holdings.

Assuming $\theta \in(0,1)$, we can write the insurance contract with Kalai bargaining as

$$
\max _{\left\{c^{i}, a^{i} \geq 0\right\}} \bar{y}+r a-\sum_{i=1}^{n} \pi^{i}\left[c^{i}+a^{\prime i}-R^{-1} \Pi\left(a^{i}\right)\right]
$$

subject to (2) for all $i=1, \ldots, n$ and

$$
(1-\theta)\left[\sum_{i=1}^{n} \pi^{i}\left(u\left(c^{i}\right)+\beta v\left(a^{\prime i}\right)\right)-\Omega(a)\right]-\theta\left[\bar{y}+r a-\sum_{i=1}^{n} \pi^{i}\left(c^{i}+a^{\prime i}-R^{-1} \Pi\left(a^{\prime i}\right)\right)\right]=0 .
$$

The insurer's profits are maximized subject to the agent's incentive-compatibility constraint and the proportional surplus-splitting rule.

Since the insurer observes the output realization $y^{i}$ and there are no private information issues or intratemporal commitment problems, it is optimal that the agent receives full insurance-that is, $c^{i}=c$ for all $i$. Formally, this can be shown by taking the first-order conditions with respect to $c^{i}$ in the constrained maximization problem above and noticing that they are fully symmetric with respect to $i$. Intuitively, the risk-averse agent is fully insured against his idiosyncratic income fluctuations and all income risk is absorbed by the risk-neutral insurer. Unlike in alternative settings (e.g., with moral hazard or adverse selection), here there are no gains from making the agent's consumption state-contingent since output realizations are exogenous and not affected by any agent actions or type. Assuming a symmetric solution, we also obtain $a^{\prime i}=a^{\prime}$ for all $i$. In this case (which is assumed hereafter), the insurance contract can be written as

$$
\max _{c, a^{\prime} \geq 0} \bar{y}+r a-c-a^{\prime}+R^{-1} \Pi\left(a^{\prime}\right)
$$

subject to

$$
u_{c}(c)-\beta v_{a}\left(a^{\prime}\right) \geq 0 \text {, with equality if } a^{\prime}>0
$$

and 


$$
(1-\theta)\left[u(c)+\beta v\left(a^{\prime}\right)-\Omega(a)\right]-\theta\left[\bar{y}+r a-c-a^{\prime}+R^{-1} \Pi\left(a^{\prime}\right)\right]=0 .
$$

We formally define an MPE and a Markov-perfect insurance contract in our setting as follows.

Definition 1 Consider a risk-averse agent with autarky value $\Omega(a)$, as defined in (1), and bargaining power $\theta \in(0,1)$ contracting with a risk-neutral insurer.

(i) An MPE is a set offunctions $\{\mathcal{C}, \mathcal{A}, v, \Pi\}: \mathbb{A} \rightarrow \mathbb{R} \times \mathbb{A} \times \mathbb{R} \times \mathbb{R}_{+}$defined such that, for all $a \in \mathbb{A}$ :

$$
\{\mathcal{C}(a), \mathcal{A}(a)\}=\underset{c, a^{\prime} \geq 0}{\operatorname{argmax}} \bar{y}+r a-c-a^{\prime}+R^{-1} \Pi\left(a^{\prime}\right),
$$

subject to (4) and (5), and where

$$
\begin{aligned}
& v(a)=u(\mathcal{C}(a))+\beta v(\mathcal{A}(a)) \\
& \Pi(a)=\bar{y}+r a-\mathcal{C}(a)-\mathcal{A}(a)+R^{-1} \Pi(\mathcal{A}(a)) .
\end{aligned}
$$

(ii) For any $a \in \mathbb{A}$, the Markov-perfect contract implied by an MPE is the transfer schedule:

$$
\mathcal{T}(a)=\mathcal{C}(a)+\mathcal{A}(a)-r a
$$

Solving for an MPE involves finding a fixed point in the agent's value function $v$ and the insurer's profit function $\Pi$. We briefly characterize the properties of the MPE with bargaining using the first-order conditions of the insurance problem. With Lagrange multipliers $\mu$, $\lambda$, and $\zeta$ associated with the constraints (4), (5), and $a^{\prime} \geq 0$, respectively, the first-order conditions are

$$
\begin{gathered}
-1+\mu u_{c c}(c)+\lambda\left\{(1-\theta) u_{c}(c)+\theta\right\}=0 \\
-1+R^{-1} \Pi_{a}\left(a^{\prime}\right)-\mu \beta v_{a a}\left(a^{\prime}\right)+\lambda\left\{(1-\theta) \beta v_{a}\left(a^{\prime}\right)-\theta\left[-1+R^{-1} \Pi_{a}\left(a^{\prime}\right)\right]\right\}+\zeta=0 .
\end{gathered}
$$

The values of the Lagrange multipliers-specifically, whether or not they are zero-are critical to understanding the equilibrium properties.

Lemma 1 In an MPE, the Lagrange multiplier on the surplus-splitting rule (5) is positive-that is, $\lambda>0$.

Proof. Rearrange (6) as $\lambda\left\{(1-\theta) u_{c}(c)+\theta\right\}=1-\mu u_{c c}$. Given that $u_{c}>0$ and $\theta>0$, the sign of $\lambda$ is the same as the sign of the right-hand side. Since (4) is an inequality constraint, $\mu \geq 0$. Thus, given $u_{c c}<0$, the right-hand side of the previous expression is strictly positive, which implies $\lambda>0$.

If, in addition, $\mu>0$, then (4) implies an interior solution for future assets, and so $\zeta=0 .{ }^{3}$ Conditions (6) and (7) can then be solved to obtain the values of $\mu$ and $\lambda$. The optimal consumption and savings $\left(c, a^{\prime}\right)$ implied by the Markov-perfect contract with an interior solution for assets are characterized by 


$$
u_{c}(c)=\beta v_{a}\left(a^{\prime}\right)
$$

and

$$
(1-\theta)\left[u(c)+\beta v\left(a^{\prime}\right)-\Omega(a)\right]=\theta\left[\bar{y}+r a-c-a^{\prime}+R^{-1} \Pi\left(a^{\prime}\right)\right] .
$$

We further describe the properties of the MPE insurance contracts numerically in Section 4.1.

3.2.1 Discussion. If assets are contractible and there is a strictly positive rate of return differential between the parties (the case $R>r$ ), it would be optimal for assets to be carried over time at the higher rate $R$. However, since in our setting the insurer cannot commit to future transfers, the only way it could take over all the agent's assets would be to appropriately compensate him today. Doing so would imply inducing disproportionately high consumption today, which is not optimal for intertemporal smoothing reasons. This implies that the agent carries assets over time at the lower rate $r$. Note that the key problem is that the insurer is unable to commit to a long-term disbursement of the returns from assets through future transfers. In contrast, if the insurer could commit to an infinitely long contract, one can show that it is optimal to extract all of the agent's assets at the initial date (see Karaivanov and Martin, 2015, for details).

When assets are non-contractible, the agent can use savings to influence his future outside option $\Omega\left(a^{\prime}\right)$. Hence, a conflict between the parties arises whenever the insurer has market power. The insurer would prefer the agent to hold less assets, which implies higher demand for market insurance by the agent because of his lower ability to self-insure and, thus, higher profits for the insurer. In contrast, the agent would prefer larger future assets, $a^{\prime}$, which would raise his outside option, $\Omega\left(a^{\prime}\right)$, by providing a better ability to self-insure. The interplay of these incentives is illustrated in the numerical analysis below.

\subsection{Special Cases: Monopoly and Perfect Competition}

We previously wrote the Markov-perfect insurance problem for any $\theta \in(0,1)$. To gain more intuition about the properties of its solution, we describe what happens in two limiting cases-as $\theta$ goes to 0 or 1 . The limiting case $\theta \rightarrow 0$ implies that the agent has no bargaining power and corresponds to the case of a monopolist insurer. Note that as $\theta \rightarrow 0$, the surplussplitting rule (5) converges to $u(c)+\beta v\left(a^{\prime}\right)=\Omega(a)$. Since the agent's value in an MPE is $v(a)=$ $u(\mathcal{C}(a))+\beta v(\mathcal{A}(a))$, it follows that $v(a)=\Omega(a)$; that is, the agent always receives present value equal to his outside option. In other words, when the agent faces a monopolist insurer, the insurer receives all gains from the contract and the agent receives the same value as in autarky. Note that this applies regardless of whether constraint (4) binds. However, as we show in the numerical analysis, the savings decision of the agent affects, in general, the profits that the insurer can extract.

The other limiting case, $\theta \rightarrow 1$, can be interpreted as the agent having maximum bargaining power (and the insurer having zero bargaining power) and corresponds to the setting of perfect competition (free entry by insurers). Note that as $\theta \rightarrow 1$, the surplus-splitting rule (5) converges to $\bar{y}+r a-c-a^{\prime}+R^{-1} \Pi\left(a^{\prime}\right)=0$. Since in an $\operatorname{MPE} \Pi(a)=\bar{y}+r a-\mathcal{C}(a)-$ 
$\mathcal{A}(a)+R^{-1} \Pi(\mathcal{A}(a))$, this implies $\Pi(a)=0$; that is, the insurer receives zero expected present value profits. This holds for all asset levels $a \in \mathbb{A}$ and all periods. In turn, this implies that $\Pi(a)=\bar{y}+r a-\mathcal{C}(a)-\mathcal{A}(a)=0$, or equivalently, $\Pi(a)=\bar{y}-\mathcal{T}(a)=0$. In other words, if $\theta \rightarrow 1$, the insurer makes zero expected profits per period. Since this also implies that $\Pi_{a}(a)=0$ for all $a \in \mathbb{A}$, as $\theta \rightarrow 1$ the first-order conditions (6) and (7) simplify to

$$
\begin{aligned}
-1+\mu u_{c c}(c)+\lambda & =0 \\
-1-\mu \beta v_{a a}\left(a^{\prime}\right)+\lambda & =0 .
\end{aligned}
$$

As shown in Proposition 5 in Karaivanov and Martin (2015), with free entry by insurers the agent's value function $v(a)$ is strictly concave. Thus, $v_{a a}<0$, which, together with $u_{c c}<0$, implies that the above conditions are satisfied if and only if $\mu=0$. Intuitively, when the agent receives all the surplus from the risk-sharing contract, there is no misalignment between the insurer and the agent in the values of assets to be held in savings and, thus, how much assets to save and, thus, the incentive-compatibility constraint (4) does not bind.

\section{THE ROLE OF ASSET CONTRACTIBILITY}

\subsection{Theoretical Analysis}

Does asset contractibility matter for the degree of insurance and the time profiles of consumption and savings? In other words, how important is it for risk-sharing whether the insurer can or cannot bind the agent to a specific savings level? To answer these questions, we investigate whether, and under what conditions, the incentive-compatibility constraint (4) binds in an MPE. If the constraint does not bind, then whether saving decisions can or cannot be contracted on would not matter for risk-sharing. If the constraint does bind, however, then clearly the agent and the insurer have conflicting views of what savings should be. In the proposition below, we show that asset contractibility generally does matter for the contract terms.

Proposition 1 In an MPE, if $\Pi_{a}\left(a^{\prime}\right)<0$ for some $a \in \mathbb{A}$ such that $a^{\prime}=\mathcal{A}(a)>0$, then the incentive-compatibility constraint (4) binds-that is, the Lagrange multiplier $\mu$ is positive.

Proof. Suppose $\mu=0$. Then (6) and Lemma 1 imply $1-\lambda \theta=\lambda(1-\theta) u_{c}(c)>0$. Since $a^{\prime}>0$, we have $\zeta=0$ and so we can rearrange (7) as

$$
R^{-1} \Pi_{a}\left(a^{\prime}\right)(1-\lambda \theta)=\lambda(1-\theta)\left[u_{c}(c)-\beta v_{a}\left(a^{\prime}\right)\right]
$$

The left-hand side is negative since, by assumption, $\Pi_{a}\left(a^{\prime}\right)<0$ and since, as shown above, $1-\lambda \theta>0$. The right-hand side, however, is nonnegative by (4), $\lambda>0$, and $\theta \in(0,1)-\mathrm{a}$ contradiction.

Proposition 1 shows that as long as the insurer's profits are strictly decreasing in the agent's assets for some $a^{\prime}>0$ in $\mathbb{A}$ at which the agent is not borrowing constrained, then Markov-perfect insurance contracts in which the insurer is able to specify and control agent savings (equivalently consumption) differ from Markov-perfect contracts in which the insurer 
is unable to do so. That is, asset contractibility matters for any asset level $a$ satisfying the proposition conditions. Insurer's profits that monotonically decrease in the agent's assets (holding bargaining power $\theta$ constant) naturally arise-for example, if the agent's preferences exhibit decreasing absolute risk aversion. In that case, richer agents have lower demand for market insurance (they can do more smoothing with their own assets) compared with poorer agents. The borrowing constraint $a^{\prime} \geq 0$ is also less likely to bind for richer agents. See Section 4.2 for an illustration.

We can gain more intuition by looking at the special cases when $\theta$ approaches its bounds. As shown in Karaivanov and Martin (2013), in the monopolistic insurer case (when $\theta \rightarrow 0$ ), if $u$ is unbounded below and satisfies a mild technical condition, MPE contracts with and without asset contractibility differ and asset contractibility affects the insurer's profits. The reason is that the commitment friction creates a misalignment in the asset accumulation incentives of the contracting parties. Intuitively, the agent can use his ability to save privately to increase his outside option, since $\Omega$ is strictly increasing in $a$, thereby ensuring higher future transfers. This strategy counters the principal's desire, coming from profit maximization, to drive the agent toward the lower utility bound $\Omega(0)$.

As $\theta \rightarrow 1$ - the case of free entry by insurers-we showed that (i) the insurer makes zero expected profits per period for all assets levels $a$ and (ii) $\mu=0$, the savings incentivecompatibility constraint (4) does not bind. In this case, since all of the surplus goes to the agent, the objectives of the two sides are perfectly aligned. And because the insurer makes zero expected profits per period, asset contractibility is irrelevant: The insurance contract is the same, regardless of whether the insurer can control the agent's savings. The result that the insurer makes zero profits per period with free entry is critical, as it does not allow the insurer to exploit his rate of return advantage when $r<R$ if assets are contractible.

\subsection{Numerical Analysis}

We illustrate and quantify the effects of asset contractibility in Markov-perfect insurance contracts using a numerical simulation. We adopt the parameterization we used previously (Karaivanov and Martin, 2015). Specifically, suppose $u(c)=\ln c$ and pick the following parameter values: $\beta=0.93, r=1.06, R=1.07, y^{1}=0.1, y^{2}=0.3$, and $\pi^{1}=\pi^{2}=0.5$. These parameters imply expected output $\bar{y}=0.2$. For market power, we choose $\theta=0.5$ as the benchmark and analyze the effects of varying it below.

We use the following method to compute the various cases. We begin by computing the autarky problem. We use a discrete grid of 100 points for the asset space but allow all choice variables to take any admissible value. Cubic splines are used to interpolate between grid points. The upper bound for assets $\bar{a}$ is set to 5 , which ensures that the asset accumulation functions always cross the 45-degree line (i.e., the upper bound is never restrictive). Next we compute the MPE assuming $\theta=1$ (perfect competition), since in this case asset contractibility does not matter. We use the first-order conditions of the autarky and MPE problems to compute the numerical solutions for each case. Having solved the MPE with $\theta=1$, we use it as the starting point to compute an MPE for other assumptions on market power and asset contractibility. These problems are solved using standard value function iteration methods. 


\section{Figure 1}

\section{Consumption and Savings}

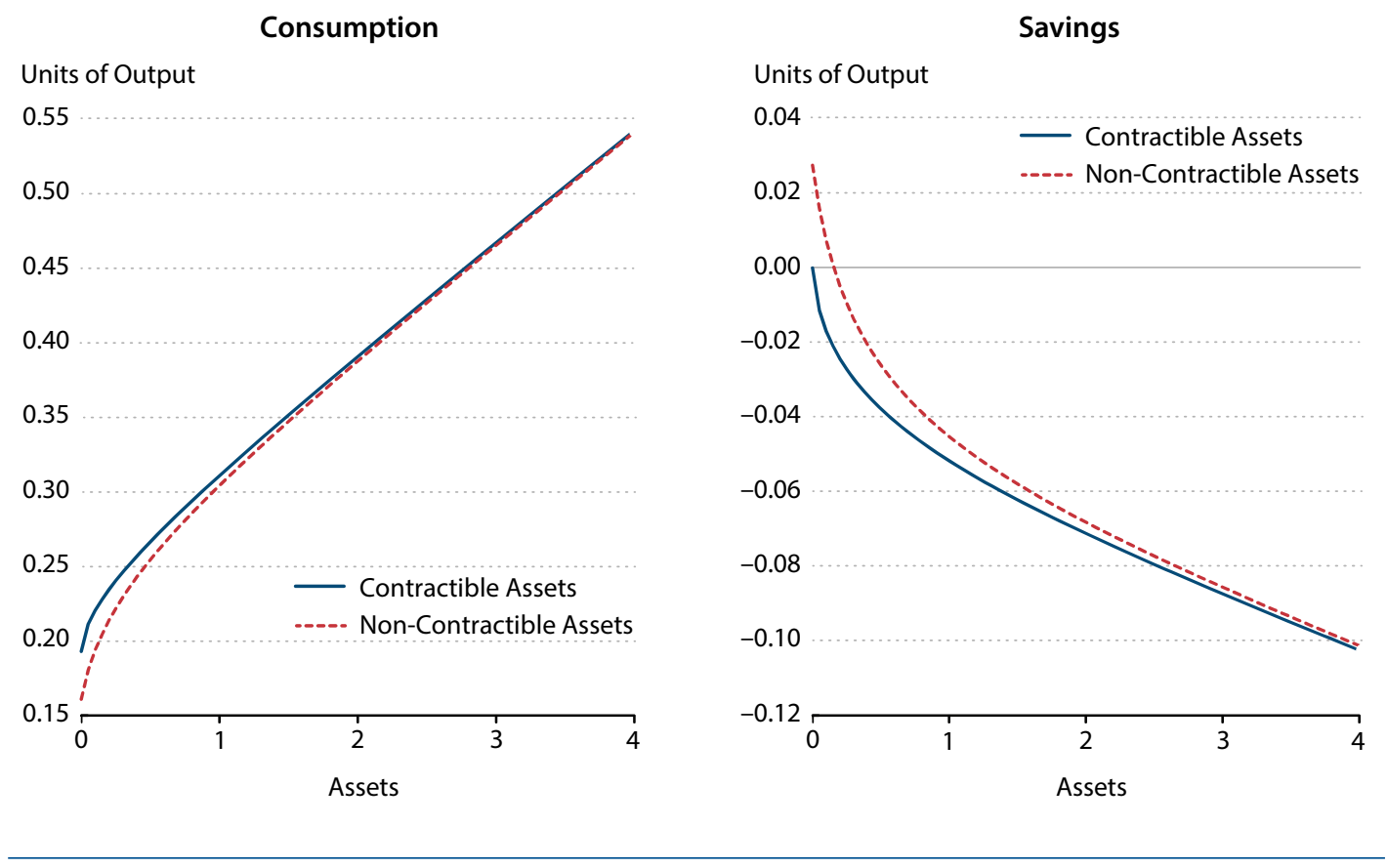

Figure 1 displays the agent's consumption $c$ and net savings $a^{\prime}-a$ as a function of the agent's current asset level $a$. The solid line corresponds to the case with contractible assets (i.e., when constraint (4) is not imposed). The dashed line corresponds to the case when the agent's choice of $a^{\prime}$ is not contractible (i.e., when constraint (4) is imposed). As shown, the agent's consumption is strictly increasing in his assets, while net savings are decreasing in assets. Allowing the savings decision to be part of the insurance contract results in higher consumption and lower savings for the agent. Intuitively, when assets are contractible, the insurer wants to push the agent's assets toward zero as this generates a lower outside option for the agent and more profits for the insurer. In addition, less assets are carried over time at the agent's rate of return $r$ instead of the higher return $R$.

The long-run implications of asset contractibility are also significantly different. When the agent's assets are not contractible, if we start with an agent with some initial assets $a_{0}$ and use the computed MPE to simulate the insurance contract for infinitely many periods, then the agent's assets converge in the limit to a positive value. This is shown by the dashed line in the right panel of Figure 1, which shows that savings $a^{\prime}-a$ is above zero for sufficiently low asset values and below zero for sufficiently high asset levels. In contrast, when savings are contractible, the agent's assets converge to zero in finite time, as proven in Karaivanov and Martin (2015).

Figure 2 shows the implications of asset (non-)contractibility for the agent's welfare and the insurer's profits. Agent welfare is measured as the per-period consumption equivalent 


\section{Figure 2}

\section{Welfare and Profits}

Agent's Welfare

Consumption Equivalent Compensation (percent)

0.8

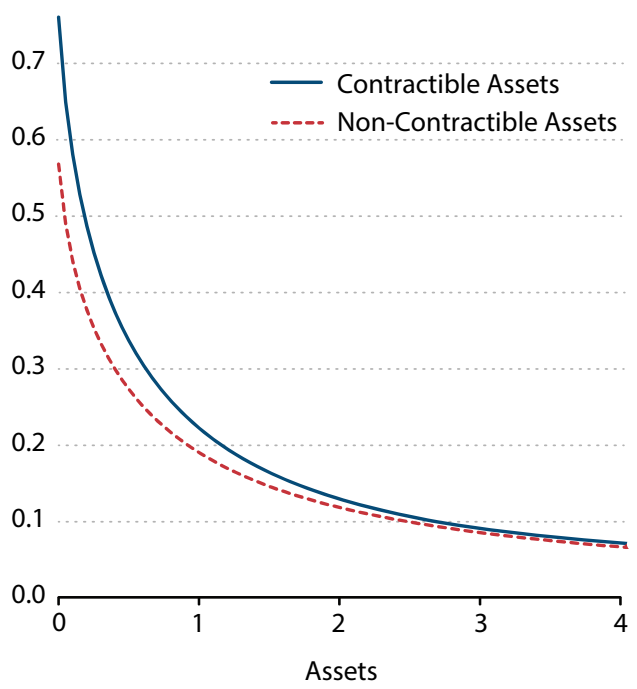

Insurer's Profits

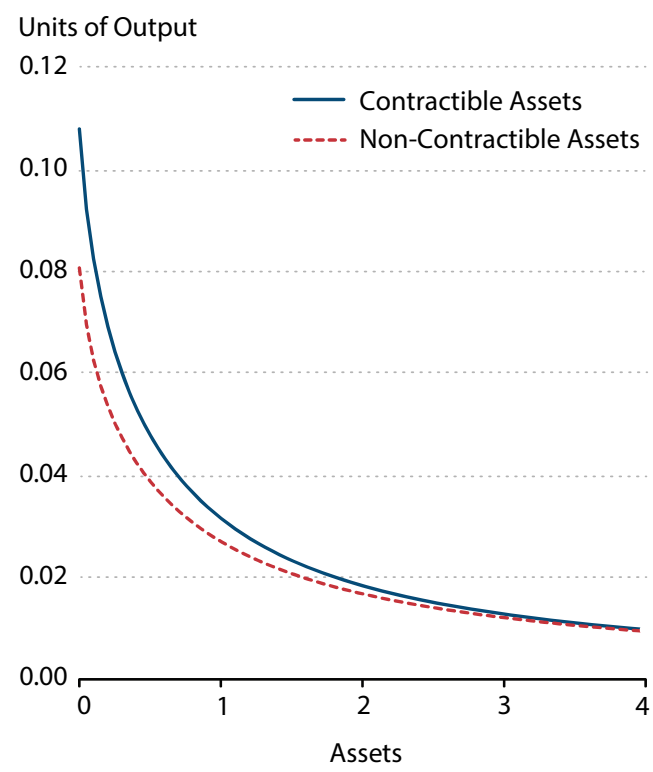

compensation the agent would require in autarky to be indifferent between remaining in autarky and accepting the insurance contract. Formally, for any $a \in \mathbb{A}$, we define the welfare gains as

$$
\Delta(a) \equiv \exp \{(1-\beta)[v(a)-\Omega(a)]\}-1 .
$$

The insurer's profits are measured as the expected net present value $\Pi(a)$, which is expressed in output units. As shown, both the agent's welfare and the insurer's profits are strictly decreasing in the agent's assets $a$. This is intuitive: At lower asset levels the agent is less able to selfinsure and therefore benefits more from additional insurance. That is, the surplus generated in an insurance contract, which is proportionally split between the parties, is larger when the agent's wealth is lower.

Note that the welfare gains for the agent in an MPE relative to self-insurance can be substantial: At the extreme, at zero assets (no ability to self-insure), they amount to almost 0.8 percent of consumption per period. The welfare gains are still significant at higher asset levels, converging toward 0.1 percent of autarky consumption per period, which is about the same as the estimated cost of business cycle fluctuations for the average agent (see Lucas, 1987). The welfare loss that arises if the agent's assets are non-contractible (the difference between the solid and dashed lines in Figure 2) can be large too: At zero assets, it is about 0.19 percent. This difference, however, becomes negligible at high asset levels. 
Turning to the insurer's profits, we see that they are the largest when the insurer contracts with an agent with zero assets (given our log utility, this corresponds to the highest demand for insurance and the least ability to self-insure). In this case, the net present value of profits equals 54 percent and 40 percent of the expected per-period output $(\bar{y}=0.2)$ for the cases with and without contractible assets, respectively. As we can see, the ability to contract on the savings decision can also significantly boost the insurer's profits, in addition to the agent's welfare.

\section{EXTENSIONS}

\subsection{Market Power}

We now analyze how the degree of the insurer's market power affects the results. That is, how do Markov-perfect insurance contracts change when we vary the bargaining power parameter $\theta$ ? The proportional surplus-splitting rule (5) directly implies that raising the agent's bargaining power $\theta$ strictly increases the agent's net surplus from market insurance, $v(a)-\Omega(a)$, relative to the insurer's present value profits $\Pi(a)$.

Using the parameterization from the previous section, we quantify the effects of market power on the agent's welfare and the insurer's profits. Figure 3 shows the consumption equivalent compensation $\Delta(a)$ and the insurer's profits at zero assets, plotted as a function of the parameter $\theta$. Recall that higher $\theta$ can be interpreted as lower market power for the insurer. As the figure shows, unsurprisingly, the agent's welfare increases with his bargaining power, while the insurer's profits decrease. As we converge to a more competitive environment (higher $\theta$ ), the agent's welfare increases considerably. In the extreme, at $\theta \rightarrow 1$ (perfectly competitive insurance market), the consumption equivalent compensation value of insurance in an MPE for an agent with zero wealth is about 4.5 percent of his autarky consumption per period. At the other extreme, when $\theta \rightarrow 0$ (monopolistic insurer), the profits of an insurer facing an agent with zero wealth are the largest, with a net present value about 65 percent of expected per period output.

Figure 3 also shows that both the agent and the insurer lose (in terms of welfare or profits) when the agent's assets are not contractible over the whole range $\theta \in(0,1)$. Interestingly, the agent's largest welfare loss from savings non-contractibility, equal to about 0.4 percent of autarky consumption, occurs at an interior value for the bargaining power parameter, at around $\theta=0.8$. Remember that the agent cannot benefit from asset contractibility in the monopoly case $(\theta \rightarrow 0)$ since in that case all gains from controlling the agent's assets go to the insurer. Also, as argued previously, the agent does not benefit from asset contractibility in the case of perfect competition $(\theta \rightarrow 1)$ since in that case the MPEs with and without asset contractibility coincide (see Sections 3.3 and 4.1). The insurer's largest loss from asset noncontractibility occurs as $\theta \rightarrow 0$ (the monopoly case), with a magnitude slightly higher than 14 percent of expected per-period output.

\subsection{The Rate of Return $R$}

We next analyze the effects of varying the insurer's intertemporal rate of return $R$. Increasing $R$ is equivalent to decreasing the factor by which the insurer discounts future 


\section{Figure 3}

\section{Market Power}

Agent's Welfare at $a=0$

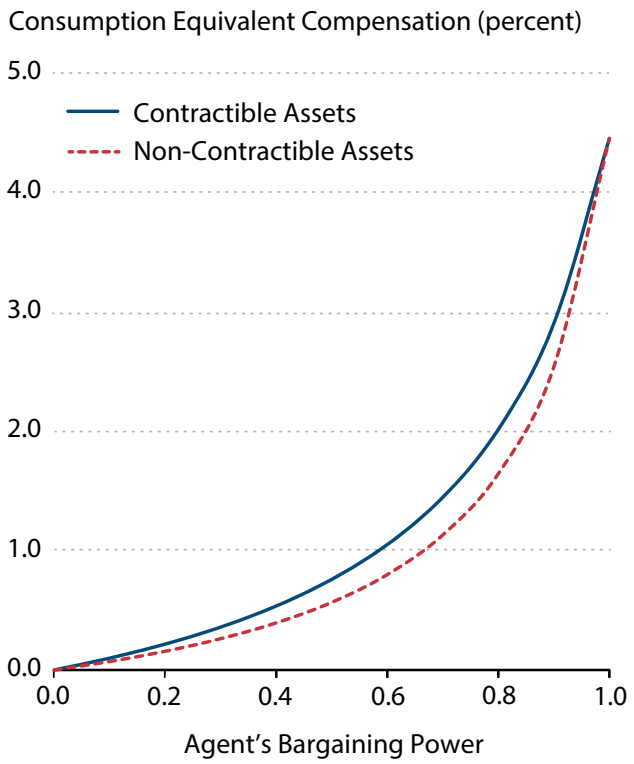

Insurer's Profits at $a=0$

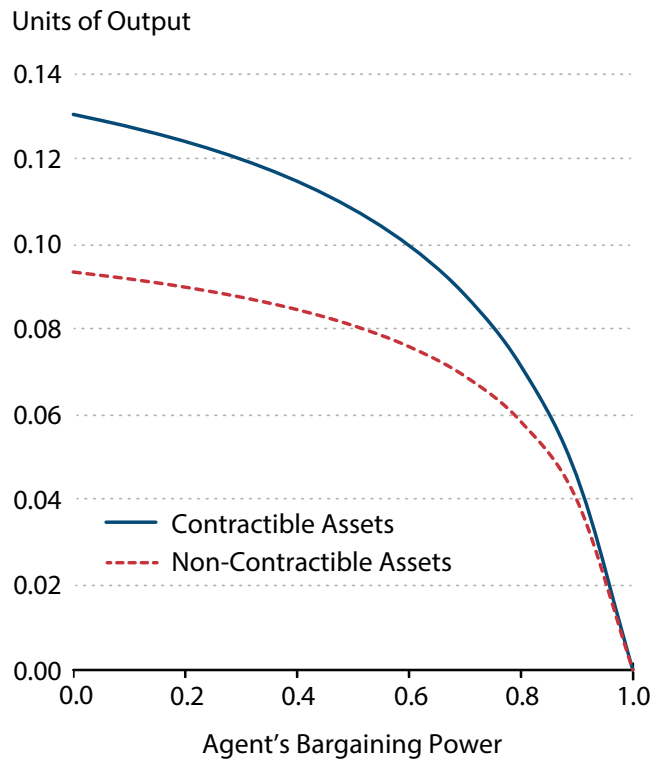

profits - that is, making the insurer more impatient. Note that there is no direct productivity effect of varying $R$ as the agent's output technology - and hence total resources - are independent of $R$. In addition, the agent's autarky problem (1) remains the same.

Figure 4 plots the agent's welfare gains in an MPE relative to self-insurance, as measured by $\Delta(a)$, and the insurer's present value profits $\Pi(a)$ as $R$ varies over its full range, from $R=r=1.06$ to $R=1 / \beta \approx 1.075$. All other parameters, including the bargaining power $\theta$, are held fixed at their respective benchmark values. In the interest of providing the clearest intuition for the results, we focus on the case of zero assets, $a=0$. All other asset levels provide a similar qualitative picture (details are available upon request).

Two main results are evident from Figure 4. First, both the agent's welfare gains relative to autarky and the present value of the insurer's profits are strictly decreasing in $R$. The intuition for this result is found by examining the direct effect of varying $R$ on the agent's and insurer's surplus in the contract. If the decision variables $c$ and $a^{\prime}$ were held fixed, the agent's surplus, $u(c)+\beta v\left(a^{\prime}\right)-\Omega(a)$, would be constant in $R$, while the insurer's surplus, $\bar{y}+r a-c-$ $a^{\prime}+R^{-1} \Pi\left(a^{\prime}\right)$, would be strictly decreasing in $R$. At $a=0$, when assets are contractible $a^{\prime}=0$ and thus, when $R$ increases, the only way to satisfy the proportional surplus-splitting constraint (5) is to decrease the agent's consumption. When $a>0$, savings decisions do vary with $R$ and, hence, there are further effects on welfare and profits. ${ }^{4}$ Our numerical simulations show that, for the chosen parameters, the overall effect still moves in the same direction as when the agent has zero assets. The difference in welfare gains as $R$ varies can be substantial. For example, 


\section{Figure 4}

\section{Rates of Return}

Agent's Welfare at $a=0$

Consumption Equivalent Compensation (percent)

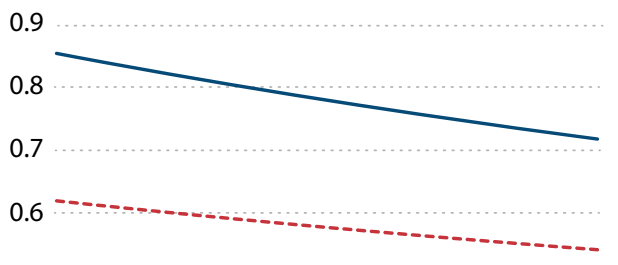

0.5

0.4

0.3

0.2

0.1

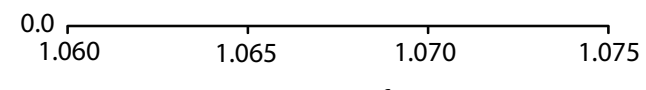

Insurer's Profits at $a=0$

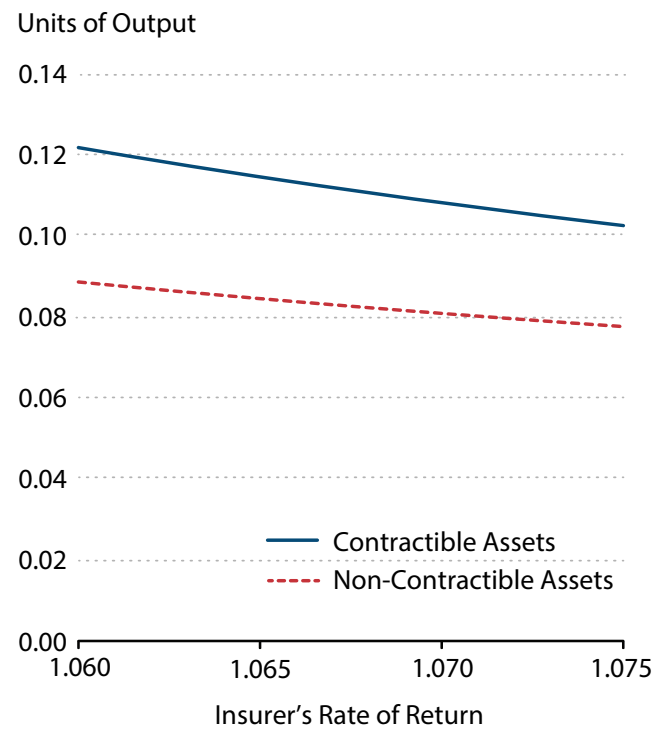

at zero assets, moving from $R \approx 1 / \beta$ to $R=r$ results in a welfare increase for the agent equivalent to 0.14 percent of his autarky consumption per period.

Second, Figure 4 shows that our results on the effects of asset (non-)contractibility continue to hold for all admissible values of $R$. Making assets contractible increases both the agent's welfare and the insurer's profits (compare the dashed lines with the solid lines). Quantitatively, at zero assets, the welfare gains from making the agent's assets contractible are the highest at $R=r=1.06$ and are equivalent to 0.23 percent of autarky consumption per period, compared with 0.19 percent at the benchmark value of $R=1.07$ or 0.18 percent at $R \approx 1 / \beta$.

\section{CONCLUSION}

We study the role of assets contractibility, market power, and the rate of return differential between insured and insurers in a dynamic risk-sharing setting with a limited commitment friction. We find significant welfare effects along all three dimensions. Potential lessons from our analysis with relevance for actual insurance markets with commitment frictions similar to those we model indicate the desirability of increased competition, extending the ability to condition insurance terms on both the current assets and the savings of the insured, as well as mitigating the possibility of a large return on assets differentials between insurance providers and households or firms. 


\section{NOTES}

1 Throughout the article, we use subscripts to denote partial derivatives and primes for next-period values.

2 That is, the agent would not save if output were constant over time.

3 Generically, an interior solution for asset choice implies $a^{\prime}>0$. However, it is possible to have an interior solution, where $a^{\prime}=0$ and where the nonnegativity constraint, although satisfied with equality, does not bind. In either case, $\zeta=0$.

4 In particular, the agent would prefer to contract with an insurer whose intertemporal rate of return $R$ is closer to the agent's rate of return $r$ as this mitigates the distortion in the time profiles of consumption and savings arising from the commitment friction (see Karaivanov and Martin, 2015, Section 3.2 for additional details).

\section{REFERENCES}

Aiyagari, S. Rao. “Uninsured Idiosyncratic Risk and Aggregate Saving." Quarterly Journal of Economics, August 1994, 109(3), pp. 659-84; http://dx.doi.org/10.2307/2118417.

Allen, Franklin. "Repeated Principal-Agent Relationships with Lending and Borrowing." Economics Letters, 1985, 17(1-2), pp. 27-31; http://dx.doi.org/10.1016/0165-1765(85)90121-1.

Arnott, Richard and Stiglitz, Joseph E. "Moral Hazard and Nonmarket Institutions: Dysfunctional Crowding Out of Peer Monitoring?" American Economic Review, March 1991, 81(1), pp. 179-90.

Bester, Helmut and Strausz, Roland. "Contracting with Imperfect Commitment and the Revelation Principle: The Single Agent Case." Econometrica, July 2001, 69(4), pp. 1077-98; http://dx.doi.org/10.11111/1468-0262.00231.

Bewley, Truman F. "The Permanent Income Hypothesis: A Theoretical Formulation." Journal of Economic Theory, December 1977, 16(2), pp. 252-92; http://dx.doi.org/10.1016/0022-0531(77)90009-6.

Cole, Harold L. and Kocherlakota, Narayana R. "Efficient Allocations with Hidden Income and Hidden Storage." Review of Economic Studies, July 2001, 68(3), pp. 523-42; http://dx.doi.org/10.1111/1467-937X.00179.

Doepke, Matthias and Townsend, Robert M. “Dynamic Mechanism Design with Hidden Income and Hidden Actions." Journal of Economic Theory, January 2006, 126(1), pp. 235-85; http://dx.doi.org/10.1016/j.jet.2004.07.008.

Fernandes, Ana and Phelan, Christopher. "A Recursive Formulation for Repeated Agency with History Dependence." Journal of Economic Theory, April 2000, 91(2), pp. 223-47; http://dx.doi.org/10.1006/jeth.1999.2619.

Kalai, Ehud. "Proportional Solutions to Bargaining Situations: Interpersonal Utility Comparisons." Econometrica, October 1977, 45(7), pp. 1623-30; http://dx.doi.org/10.2307/1913954.

Karaivanov, Alexander K. and Martin, Fernando M. "Dynamic Optimal Insurance and Lack of Commitment." Working Paper No. 2011-029, Federal Reserve Bank of St. Louis, October 2011, revised July 2013; https://research.stlouisfed.org/wp/more/2011-029.

Karaivanov, Alexander K. and Martin, Fernando M. "Dynamic Optimal Insurance and Lack of Commitment." Review of Economic Dynamics, April 2015, 18(2), pp. 287-305; http://dx.doi.org/10.1016/j.red.2014.05.001.

Lucas, Robert E. Jr. Models of Business Cycles. Oxford, England: Basil Blackwell, 1987.

Maskin, Eric and Tirole, Jean. "Markov Perfect Equilibrium: I. Observable Actions." Journal of Economic Theory, October 2001, 100(2), pp. 191-219; http://dx.doi.org/10.1006/jeth.2000.2785.

Schechtman, Jack and Escudero, Vera L.S. "Some Results on an 'Infinite Fluctuation Problem.'” Journal of Economic Theory, December 1977, 16(2), pp. 151-66; http://dx.doi.org/10.1016/0022-0531(77)90003-5.

Stokey, Nancy L.; Lucas, Robert E. Jr. and Prescott, Edward C. Recursive Methods in Economic Dynamics. Cambridge, MA: Harvard University Press, 1989. 
